\title{
Increased hippocampal volume and gene expression following cognitive behavioral therapy in PTSD
}

\author{
Ahmed A. Moustafa * \\ Marcs Institute for Brain and Behaviour, School of Social Sciences and Psychology, University of Western Sydney, Sydney, NSW, Australia \\ *Correspondence: a.moustafa@uws.edu.au \\ Edited by: \\ Alexander J. Shackman, University of Maryland, USA \\ Reviewed by: \\ Talma Hendler, Tel Aviv University and Tel Aviv Medical Center, Israel
}

Keywords: PTSD, hippocampus, amygdala, neurogenetics, cognitive behavioral therapy, computational modeling

\section{A commentary on}

Association among clinical response, hippocampal volume, and FKBP5 gene expression in individuals with posttraumatic stress disorder receiving cognitive behavioral therapy

by Levy-Gigi, E., Szabo, C., Kelemen, O., and Keri, S. (2013). Biol. Psychiatry. doi: 10.1016/j.biopsych.2013.05.017

In a recent study in Biological Psychiatry, Levy-Gigi et al. found that a 12 weekly 90mins cognitive behavioral therapy (CBT) treatment in individuals with posttraumatic stress disorder (PTSD) is associated with an increase in hippocampal volume and expression of glucocorticoid receptor genes, known as FKBP5 (Levy-Gigi et al., 2013). This is one of the few studies that have investigated the effects of CBT on changes in brain volumes as well as gene expression in individuals with PTSD. The Levy-Gigi et al. study complements prior studies showing that antidepressant treatment is also associated with increased hippocampal volume in psychiatric patients, including PTSD and depression (Vermetten et al., 2003). Despite the positive effect of psychopharmacological and behavioral therapy in PTSD, it is not known whether CBT and psychopharmacological treatments are associated with dissociable effects on the brain and behavior.

Interestingly, Levy-Gigi et al. found that CBT ameliorates all aspects of PTSD, including avoidance, re-experiencing, and hyperarousal symptoms. However, it is not clear from the Levy-Gigi et al. study whether changes to the hippocampal volume are associated with amelioration to which PTSD symptoms. Prior studies show that there is a trend for a negative correlation between higher reexperiencing symptoms and hippocampal volume (Shucard et al., 2012), perhaps suggesting that re-experiencing symptoms are more ameliorated than other PTSD symptoms following CBT treatment.

At the neural level, several studies show that PTSD is associated with abnormalities to various brain areas, including reduced activity and volume of the hippocampus (Gilbertson et al., 2002; Smith, 2005), reduced activity of the ventromedial prefrontal cortex (Shin et al., 2005; Phan et al., 2006), increased activity of the dorsal anterior cingulate cortex (Shin et al., 2011), and increased activity of the amygdala (Armony et al., 2005; Shin et al., 2005). However, why would CBT lead to changes to the volume of the hippocampus but not the amygdala or other cortical structures, as found in the Levy-Gigi et al. study? Prior studies have shown the hippocampal volume is a risk factor for the development of PTSD (Gilbertson et al., 2002), while changes to amygdala, the ventromedial prefrontal cortex, and dorsal anterior cingulate cortex are acquired following trauma exposure. This perhaps suggests that changes to hippocampal volume following CBT can help protect against future occurrences of PTSD symptoms.

How can hippocampal dysfunction be related to PTSD symptoms? As noted by Levy-Gigi et al., the ventral hippocampusamygdala pathway has been shown to be related to increased stress and anxiety (Fanselow and Dong, 2010). Further, many animal and human studies show that the hippocampus is involved in contextual fear responses (Anagnostaras et al., 1999; Corcoran and Maren, 2001; Ji and Maren, 2007; Acheson et al., 2012), such that hippocampal damage leads to increased fear response regardless of the context. fMRI studies have also reported greater hippocampus activation during contextual than cue conditioning (Marschner et al., 2008). In a prior computational model, Moustafa et al. (2013) show that the hippocampal region processes contextual information and sends representations of context to the basolateral amygdala and ventromedial prefrontal cortex for fear acquisition and extinction learning [for a review, see Rudy et al. (2004); Goosens (2011)], which help decrease and increase fear responses within that context. It is also not clear in the Levi-Gigi et al. study how changes to the hippocampal volume ameliorate PTSD symptoms. Moustafa et al. (2013) suggest that hippocampal projections to the ventromedial prefrontal cortex and/or basolateral amygdala could be enhanced by CBT treatment, which then lead to a decrease in fear responses when faced with a reminder of the trauma. This hypothesis can be confirmed or disconfirmed using diffusion tensor imaging in both individuals and animal models of PTSD [see for example Ding et al. (2013)].

The Levy-Gigi et al. study also showed that CBT alters the expression of genes, including the FKBP5 gene. FKBP5 regulates glucocorticoid receptor sensitivity, and reduce the efficacy of cortisol in the brain (Mahon et al., 2013). Polymorphisms in the FKBP5 gene relate to differences in glucocorticoid receptor sensitivity and stress hormone system regulation (Menke et al., 2013) as well as recovery from stress disorders (Ising et al., 2008) and rapid response to antidepressant treatment (Binder et al., 2004). As noted by Levy-Gigi et al., individual differences in the FKBP5 gene are associated 
with anxiety disorders, including PTSD (Xie et al., 2010; Boscarino et al., 2012).

Along these lines, Felmingham et al. (2013) found that individual differences in the brain-derived neurotrophic factor (BDNF) gene predicts the efficacy of exposure therapy in individuals with PTSD. It remains to be shown whether BDNF gene expression also undergoes changes following either CBT or exposure therapy, and whether exposure therapy affects the hippocampal volume.

Future computational modeling work is needed to explain how changes to the hippocampal volume and gene expression can ameliorate PTSD symptoms [see for example Krasne et al. (2011); Li et al. (2011); Moustafa et al. (2013)]. These computational models should also tie together brain volume and gene expression data in one framework to explain how clinical treatments can ameliorate symptoms in PTSD.

In summary, Levy-Gigi et al. (2013) have extended prior studies and shown that the hippocampus is a key brain structure that benefits from CBT. Future work should focus on network changes of hippocampus projections to the amygdala and ventromedial prefrontal cortex during behavioral and psychopharmacological treatments in PTSD.

\section{REFERENCES}

Acheson, D. T., Gresack, J. E., and Risbrough, V. B. (2012). Hippocampal dysfunction effects on context memory: possible etiology for posttraumatic stress disorder. Neuropharmacology 62, 674-685. doi: 10.1016/j.neuropharm.2011.04.029

Anagnostaras, S. G., Maren, S., and Fanselow, M. S. (1999). Temporally graded retrograde amnesia of contextual fear after hippocampal damage in rats: within-subjects examination. J. Neurosci. 19, 1106-1114.

Armony, J. L., Corbo, V., Clement, M. H., and Brunet, A. (2005). Amygdala response in patients with acute PTSD to masked and unmasked emotional facial expressions. Am. J. Psychiatry 162, 1961-1963. doi: 10.1176/appi.ajp.162.10.1961

Binder, E. B., Salyakina, D., Lichtner, P., Wochnik, G. M., Ising, M., Putz, B., et al. (2004). Polymorphisms in FKBP5 are associated with increased recurrence of depressive episodes and rapid response to antidepressant treatment. Nat. Genet. 36, 1319-1325. doi: 10.1038/ng1479

Boscarino, J. A., Erlich, P. M., Hoffman, S. N., and Zhang, X. (2012). Higher FKBP5, COMT, CHRNA5, and CRHR1 allele burdens are associated with PTSD and interact with trauma exposure: implications for neuropsychiatric research and treatment. Neuropsychiatr. Dis. Treat. 8, 131-139. doi: 10.2147/NDT.S29508

Corcoran, K. A., and Maren, S. (2001). Hippocampal inactivation disrupts contextual retrieval of fear memory after extinction. J. Neurosci. 21, 1720-1726.

Ding, A. Y., Li, Q., Zhou, I. Y., Ma, S. J., Tong, G., McAlonan, G. M., et al. (2013). MR diffusion tensor imaging detects rapid microstructural changes in amygdala and hippocampus following fear conditioning in mice. PLoS ONE 8:e51704. doi: 10.1371/journal.pone.0051704

Fanselow, M. S., and Dong, H. W. (2010). Are the dorsal and ventral hippocampus functionally distinct structures? Neuron 65, 7-19. doi: 10.1016/j.neuron.2009.11.031

Felmingham, K. L., Dobson-Stone, C., Schofield, P. R., Quirk, G. J., and Bryant, R. A. (2013). The brainderived neurotrophic factor Val66Met polymorphism predicts response to exposure therapy in posttraumatic stress disorder. Biol. Psychiatry 73, 1059-1063. doi: 10.1016/j.biopsych.2012.10.033

Gilbertson, M. W., Shenton, M. E., Ciszewski, A., Kasai, K., Lasko, N. B., Orr, S. P., et al. (2002). Smaller hippocampal volume predicts pathologic vulnerability to psychological trauma. Nat. Neurosci. 5, 1242-1247. doi: 10.1038/nn958

Goosens, K. A. (2011). Hippocampal regulation of aversive memories. Curr. Opin. Neurobiol. 21, 460-466. doi: 10.1016/j.conb.2011.04.003

Ising, M., Depping, A. M., Siebertz, A., Lucae, S., Unschuld, P. G., Kloiber, S., et al. (2008). Polymorphisms in the FKBP5 gene region modulate recovery from psychosocial stress in healthy controls. Eur. J. Neurosci. 28, 389-398. doi: 10.1111/j.1460-9568.2008.06332.x

Ji, J., and Maren, S. (2007). Hippocampal involvement in contextual modulation of fear extinction. Hippocampus 17, 749-758. doi: 10.1002/hipo.20331

Krasne, F. B., Fanselow, M. S., and Zelikowsky, M. (2011). Design of a neurally plausible model of fear learning. Front. Behav. Neurosci. 5:41. doi: 10.3389/fnbeh.2011.00041

Levy-Gigi, E., Szabo, C., Kelemen, O., and Keri, S. (2013). Association among clinical response, hippocampal volume, and FKBP5 gene expression in individuals with posttraumatic stress disorder receiving cognitive behavioral therapy. Biol. Psychiatry. doi: 10.1016/j.biopsych.2013.05.017. [Epub ahead of print]

Li, G., Amano, T., Pare, D., and Nair, S. S. (2011). Impact of infralimbic inputs on intercalated amygdala neurons: a biophysical modeling study. Learn. Mem. 18, 226-240. doi: 10.1101/lm.1938011

Mahon, P. B., Zandi, P. P., Potash, J. B., Nestadt, G., and Wand, G. S. (2013). Genetic association of FKBP5 and CRHR1 with cortisol response to acute psychosocial stress in healthy adults. Psychopharmacology 227, 231-241. doi: 10.1007/s00213-012-2956-x

Marschner, A., Kalisch, R., Vervliet, B. Vansteenwegen, D., and Buchel, C. (2008). Dissociable roles for the hippocampus and the amygdala in human cued versus context fear conditioning. J. Neurosci. 28, 9030-9036. doi: 10.1523/JNEUROSCI.1651-08.2008

Menke, A., Klengel, T., Rubel, J., Bruckl, T., Pfister, H., Lucae, S., et al. (2013). Genetic variation in FKBP5 associated with the extent of stress hormone dysregulation in major depression. Genes Brain Behav. 12, 289-296. doi: 10.1111/gbb.12026

Moustafa, A. A., Gilbertson, M. W., Orr S. P., Herzallah, M. M., Servatius, R. J., and Myers, C. E. (2013). A model of amygdala-hippocampal-prefrontal interaction in fear conditioning and extinction in animals. Brain Cogn. 81, 29-43. doi: 10.1016/j.bandc.2012.10.005

Phan, K. L., Britton, J. C., Taylor, S. F., Fig, L. M., and Liberzon, I. (2006). Corticolimbic blood flow during nontraumatic emotional processing in posttraumatic stress disorder. Arch. Gen. Psychiatry 63, 184-192. doi: 10.1001/archpsyc.63.2.184

Rudy, J. W., Huff, N. C., and Matus-Amat, P. (2004). Understanding contextual fear conditioning: insights from a two-process model. Neurosci. Biobehav. Rev. 28, 675-685. doi: 10.1016/j.neubiorev.2004.09.004

Shin, L. M., Bush, G., Milad, M. R., Lasko, N. B., Brohawn, K. H., Hughes, K. C., et al. (2011). Exaggerated activation of dorsal anterior cingulate cortex during cognitive interference: a monozygotic twin study of posttraumatic stress disorder. Am. J. Psychiatry 168, 979-985. doi: 10.1176/appi.ajp.2011.09121812

Shin, L. M., Wright, C. I., Cannistraro, P. A., Wedig M. M., McMullin, K., Martis, B., et al. (2005). A functional magnetic resonance imaging study of amygdala and medial prefrontal cortex responses to overtly presented fearful faces in posttraumatic stress disorder. Arch. Gen. Psychiatry 62, 273-281. doi: 10.1001/archpsyc.62.3.273

Shucard, J. L., Cox, J., Shucard, D. W., Fetter, H., Chung, C., Ramasamy, D., et al. (2012). Symptoms of posttraumatic stress disorder and exposure to traumatic stressors are related to brain structural volumes and behavioral measures of affective stimulus processing in police officers. Psychiatry Res. 204, 25-31. doi: 10.1016/j.pscychresns.2012.04.006

Smith, M. E. (2005). Bilateral hippocampal volume reduction in adults with post-traumatic stress disorder: a meta-analysis of structural MRI studies. Hippocampus 15, 798-807. doi: 10.1002/hipo.20102

Vermetten, E., Vythilingam, M., Southwick, S. M., Charney, D. S., and Bremner, J. D. (2003). Longterm treatment with paroxetine increases verbal declarative memory and hippocampal volume in posttraumatic stress disorder. Biol. Psychiatry 54, 693-702. doi: 10.1016/S0006-3223(03)00634-6

Xie, P., Kranzler, H. R., Poling, J., Stein, M. B., Anton, R. F., Farrer, L. A., et al. (2010). Interaction of FKBP5 with childhood adversity on risk for post-traumatic stress disorder. Neuropsychopharmacology 35, 1684-1692. doi: $10.1038 /$ npp. 2010.37

Received: 07 August 2013; accepted: 18 October 2013; published online: 07 November 2013.

Citation: Moustafa AA (2013) Increased hippocampal volume and gene expression following cognitive behavioral therapy in PTSD. Front. Hum. Neurosci. 7:747. doi: 10.3389/fnhum.2013.00747

This article was submitted to the journal Frontiers in Human Neuroscience.

Copyright (c) 2013 Moustafa. This is an open-access article distributed under the terms of the Creative Commons Attribution License (CC BY). The use, distribution or reproduction in other forums is permitted, provided the original author(s) or licensor are credited and that the original publication in this journal is cited, in accordance with accepted academic practice. No use, distribution or reproduction is permitted which does not comply with these terms. 